\title{
EFFECTS OF DIFFERENT CRYOGENIC TREATMENTS ON DRILLING PERFORMANCE OF HSS DRILLS
}

\author{
Simge AVCI ${ }^{1,}$ *, Tugrul SOYUSINMEZ ${ }^{2}$, Onur ERTUĞRUL ${ }^{1}$ \\ ${ }^{1}$ Department of Materials Science and Engineering, İzmir Katip Çelebi University, İzmir 35620, Turkey \\ 2 Totomak Makina ve Yedek Parça Sanayi ve Ticaret A.Ş., Ataşehir, 10002. Sk. No:4, 35620 Aosb / Çiğli / İzmir
}

\begin{abstract}
Cryogenic treatment has been widely used in recent years to improve the properties of cutting tool materials. This process has been reported in the literature as it provides significant contributions to wear resistance and tool life of tool steels. This study presents the differences in tool performance between untreated and cryogenically treated M2 high speed steel (HSS) drill bits in terms of their tool wear, tool life, hardness and chip formation properties. Also, the effects of two different tempering temperatures $\left(200^{\circ} \mathrm{C}\right.$ and $\left.250^{\circ} \mathrm{C}\right)$ in cryogenic treatment on tool performance are discussed. Drilling performances were studied on different workpieces of SAE 1050, lamellar cast iron and sphero cast iron, and the type of wear is characterized by a high resolution camera. Moreover, fracture tests were performed on a steel workpiece using a constant drilling speed of $1100 \mathrm{~m} / \mathrm{min}$ and a feed rate of $0.5 \mathrm{~mm} / \mathrm{rev}$. The microstructures of the samples were characterized using optical microscopy and SEM. The Vickers microhardness tests of the samples were performed using $100 \mathrm{~g}$ load. Microstructural studies showed that cryogenically treated samples exhibit better microstructure with finer and more homogeneous carbides which yields better tool wear and hardness properties. In paralel, cryogenically treated drills showed improved tool life than untreated drills during fracture tests. When tempering temperatures are compared, tempering at $250{ }^{\circ} \mathrm{C}$ resulted in better performance than $200{ }^{\circ} \mathrm{C}$ of tempering temperature. Also, the reduction in diameter values during drilling tests were consistent with the tool life tests.
\end{abstract}

Keywords: Cryogenic treatment, Tempering temperature, M2 high-speed steel, Tool wear, Tool life

\section{INTRODUCTION}

\subsection{High Speed Steels (HSS)}

High-speed steels (HSS) are high-carbon, high alloyed, and very hard steels in the tool steel family. They have a red hardness (hot hardness). They have high wear resistance and toughness thanks to their high alloying elements. These steels can be used for machining when high speeds are demanded. Therefore, they are mostly used as high-speed rotating component cutters and processors [1]. The main feature of high-speed steels, which are generally hardened and tempered, is the use of hard carbides such as chrome, molybdenum, vanadium and tungsten in the hot hardening matrix providing wear resistance [2]. AISI M2 steel is molybdenum based high speed steel in tungsten-molybdenum series. HSS M2 is a medium alloy HSS with good machining. HSS M2's chemical composition provides a well balanced combination. M2 steels have good abrasion resistance, red hardness properties, and toughness. Thus, they have wide application areas such as twist drills, taps, end mills, saws, sharp objects such as knives [3].

\subsection{Wear On Tool}

Cutting tools fail due to following three cases, a. Fracture of tool because of ultra shock and force, $b$. Tool wears through plastic deformation or change in chemical of physical status of tool, and c. Gradual wear like flank wear, crater wear and others [4]. The type of wear on the side surface of the tool is called flank wear. It is the most major wear that seems on the flank surface parallel to the cutting edge. Abrasive/adhesive wear of the cutting edge most usually results from against the machined surface. It

*Corresponding Author: onur.ertugrul@ikc.edu.tr

Received: 18.11.2019 Published: 31.03.2020 
occurs due to reaching high temperatures between tool and work material. It consequences in the formation of wear layer. Wear layer formation is not always uniform along the major and minor cutting edge of the tool. Flank wear occurs by abrasion in the parts of built-up edge, that hit against the flank face of the tool [5]. Crater wear is caused by a chemical interplay between the rake face of a metalcutting insert and the hot metal chips flowing over the tool. The crater wear is mainly on account of diffusion and abrasion. They are frequently observed where the continuous chip is formed usually in the ductile material [6].

\subsection{Traditional Heat Treatment Of M2}

Heat treatments are carried out in order to heat the material to the appropriate temperature and to keep it at certain temperatures and to improve the internal structure and properties by cooling it in various environments. [7]. Prior to forming and curing, all high-speed steels are softened by annealing for about 2-4 hours at $760-850{ }^{\circ} \mathrm{C}$ according to their composition, then cooled very slowly to $600{ }^{\circ} \mathrm{C}$ in the oven. They are cooled to the ambient temperature. The annealed structure consists of carbide beads dispersed in the perlite matrix [8]. Since stable carbides in the structure of high-speed steel have to be dissolved sufficiently before giving water, the quenching temperature is selected as $1200-1320^{\circ} \mathrm{C}$ just below the solidus line. Rapid heating of the steel to a high temperature of $1200^{\circ} \mathrm{C}$ causes distortions and cracking due to the low heat conduction coefficient. In addition, grain hardening and oxidation in the high hardening occurs. Also, grain growth and oxidation occurs at high hardening temperatures. For this reason, the steel is heated to this high temperature very slowly or gradually and mostly in a controlled salt bath [9]. With the rapid cooling of the steel in the cooling medium, the carbon is squeezed into the austenite phase, a rigid and stressed volume centered tetragonal structure is formed, called martensite. The martensite completion temperature falls below room temperature. Therefore, while austenitizing temperature is given to the steel, austenite is found in the structure without turning into martensite. This is called residual austenite. While the martensite in the structure is hardness and it is a structure which is stressed in the same way, it gives a fragility and due to the low hardness of the austenite, an unbalance in terms of hardness is observed. [10]. Another way to convert residual austenite to martesite in a structure other than tempering is to immerse high-speed steel cooled to room temperature in liquid nitrogen $\left(-196^{\circ} \mathrm{C}\right)$ by a process known as cryogenic processing [11].

Cryogenic treatment is an efficient method that improves the tool life-time and wear resistance of cutting tools. Cryogenic treatment enhances the wear resistance, toughness, hardness, tool life-time of not only steel based (HSS) but also carbide based cutting tools [12]. Significant parameters in cryogenic treatment that impress tool performance are cutting tool style, soaking period, soaking temperature, cooling speed and tempering process. The cryogenic process involves the steps of cooling the material at room temperature to $-273{ }^{\circ} \mathrm{C}$ following the quenching process, keeping the medium in this environment until the structural change occurs throughout the material and then allowing it to warm to room temperature. [13-15].

\subsection{Literature Overview}

There are studies about cryogenic treatment in the literature. For example; In 2012, Adem Çiçek and his team investigated the effects of deep cryogenic processing $\left(-196^{\circ} \mathrm{C}\right)$ on M35 HSS drills on tool life, tool wear, microstructure and microhardness. Three different cutting speeds $(20,25$ and $30 \mathrm{~m} / \mathrm{min})$ were performed with constant progress $(0.1 \mathrm{~mm} / \mathrm{rev})$ parameters. The cryogenic process was carried out in the vacuum furnace with protective atmosphere by the help of nitrogen in the gas phase. The cutting tools were gradually cooled from room temperature to $-196^{\circ} \mathrm{C}$ with a cooling rate of about $1.5^{\circ} \mathrm{C} / \mathrm{min}$ and then stored at this temperature for 24 hours and then returned to room temperature with a heating rate of $1.5^{\circ} \mathrm{C} / \mathrm{min}$. Later on cryogenic treatment, the tempering process was carried out at $200{ }^{\circ} \mathrm{C}$ for 2 hours. As a criterion for tool life tests, Nordtest NT Meche 038 standard is based on catastrophic failure recommended for HSS drills [16]. Another study was designed to evaluate the effects of different holding times of deep cryogenic treatment on tool wear in turning of AISI 316 austenitic stainless steel. 
The cemented carbide inserts were cryogenically treated at $\left(-145^{\circ} \mathrm{C}\right)$ for $12,24,36,48$ and $60 \mathrm{~h}$. Wear tests were conducted at four cutting speeds $(100,120,140$ and $160 \mathrm{~m} / \mathrm{min})$, a feed rate of $0.3 \mathrm{~mm} / \mathrm{rev}$ and a $2.4 \mathrm{~mm}$ depth of cut under drycutting conditions. The wear test results showed that flank wear and crater wear were present in all combinations of the cutting parameters. However, notch wear appeared only at lower cutting speeds (100 and $120 \mathrm{~m} / \mathrm{min}$ ). In general, the best wear resistance was obtained with cutting inserts cryogenically treated for $24 \mathrm{~h}$. This case was attributed to the increased hardness and improved microstructure of cemented carbide inserts [17].

This study aims to observe the effects of cryogenic treatment in comparison to conventional heat treatment. The purpose was is to obtain maximum benefit from cryogenic processing in cutting tools and to find appropriate temperature in cryogenic process parameters and to increase tool wear resistance and tool life-time owing to progress in mechanical features.

\section{MATERIALS AND METHODS}

\subsection{Cryogenic Treatment}

Chemical composition of the used M2 HSS drills are presented in Table 1. After heat treatment, the remaining austenite phase was converted to martensite by cryogenic treatment and hard carbide structures were formed [18]. To increase the hardness and wear resistance of the steel, the drills were kept at $-196^{\circ} \mathrm{C}$ for 24 hours, and with a cooling rate of $1^{\circ} \mathrm{C} / \mathrm{min}$. Three drill groups were used as untreated drills (UT) with no additional treatment and cryogenic treatment with a $2 \mathrm{~h}$ tempering at $200{ }^{\circ} \mathrm{C}$ treated drills (CTT1) and $2 \mathrm{~h}$ temper at $250^{\circ} \mathrm{C}$ treated drills (CTT2). The three group drill is shown in Figure 1.

Table 1. Chemical composition of the used M2 drills (wt.\%).

\begin{tabular}{lc}
\hline Element & Content \% \\
\hline $\mathrm{C}$ & 0.87 \\
$\mathrm{~W}$ & 6 \\
$\mathrm{Mo}$ & 4.9 \\
$\mathrm{Cr}$ & 4 \\
$\mathrm{~V}$ & 1.9 \\
$\mathrm{Si}$ & 0.4 \\
$\mathrm{Mn}$ & 0.2 \\
$\mathrm{Ni}$ & 0.2 \\
\hline
\end{tabular}

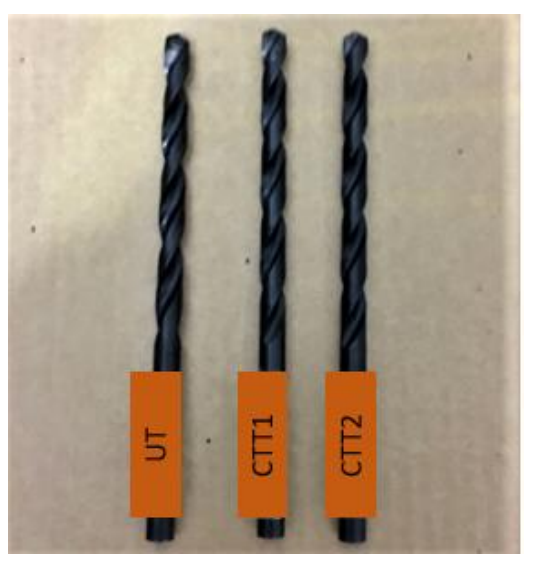

Figure 1. Three different group of drills 


\subsection{Metallography and Hardness Studies}

The cutted samples were molded using bakelite. The molded samples were grinded with $150 \mathrm{D}, 500 \mathrm{D}$, 800D, 1000D, 1200D and 2000D sandpaper respectively. The roughness of the sample surface was removed and made ready for polishing. At the polishing stage, the surface was polished and prepared for etching using 3 micron, 1 micron and 0.25 micron Diamond solution and lubricant. The etching step was carried out using a nital solution containing 0.2 nitric acid. The microstructure images were taken by optical microscope. SEM analysis of CTT1 and CTT2 drill bits were performed. Vickers microhardness tests were performed using $100 \mathrm{~g}$ load from the polished samples using six indentations, and the mean values and standart deviations have been calculated. The microhardness measuring instrument is shown in Figure 2.

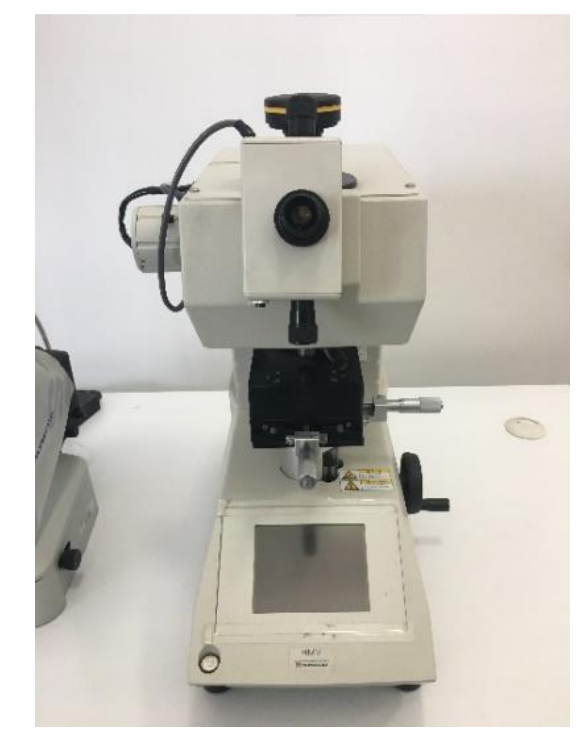

Figure 2. Microhardness measuring instrument

\subsection{Drilling Processes and Tests}

Drilling experiments were performed on CNC drilling machine. Blind holes were drilled in normalized 1050 steel blocks, sphero and lamellar cast iron blocks. Hole dept was keept constant at $15 \mathrm{~mm}$, feed rate and cutting speed shown in the Table 2.

Table 2: Drilling process parameters.

\begin{tabular}{|c|c|c|}
\hline Workpiece & Cutting speed & Feed rate \\
\hline Lamellar & $900 \mathrm{~m} / \mathrm{min}$ & $0.084 \mathrm{~mm} / \mathrm{rev}$ \\
\hline Sphero & $900 \mathrm{~m} / \mathrm{min}$ & $0.07 \mathrm{~mm} / \mathrm{rev}$ \\
\hline 1050 Steel & $840 \mathrm{~m} / \mathrm{min}$ & $0.05 \mathrm{~mm} / \mathrm{rev}$ \\
\hline
\end{tabular}

On steel, sphero and lamellar workpieces, untreated HSS, CTT1 and CTT2 drills were used to perform blind hole drilling with 10,20 and 30 specified parameters. After every 10 drilling operations, the type of wear is characterized by a high resolution camera. The appearance of wear on high resolution camera is shown in Figure 3. 


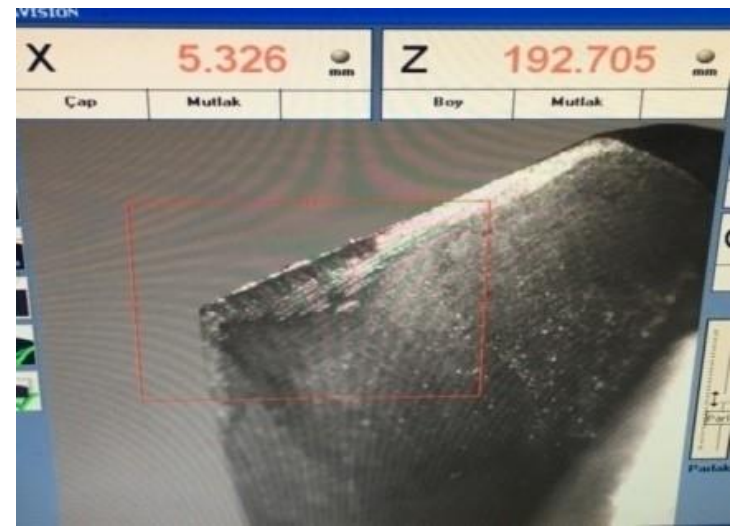

Figure 3. High resolution camera image showing wear scars of "UT" drill bit

\subsection{Fracture Studies}

For the drillings of the three groups used in the steel drilling tests, the fracture test was performed on the steel workpiece with a constant cutting speed of $1100 \mathrm{~m} / \mathrm{min}$ and the constant progress $0.5 \mathrm{~mm} /$ rev parameters. It is also used for microstructure and hardness inspection of drills used in fracture test. The steel workpiece with fracture testing and chip formation during drilling operations are shown in Figure 4 and Figure 5.

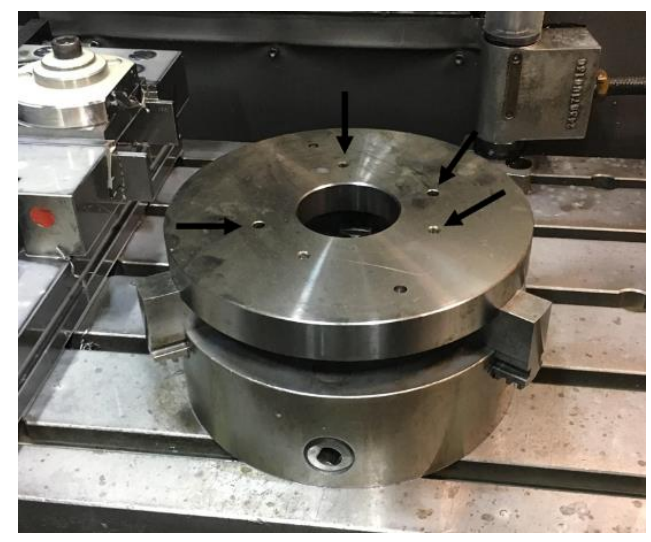

Figure 4. Steel workpiece used for fracture testing

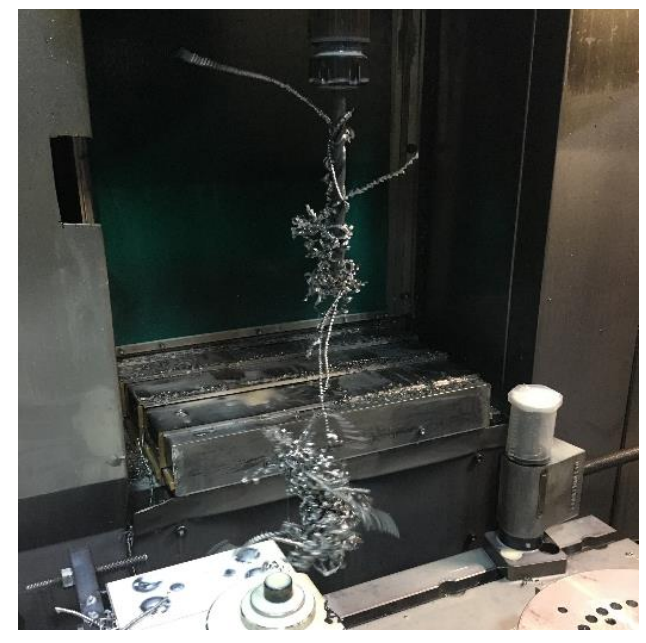

Figure 5. Chip formation during drilling operations 


\section{RESULTS AND DISCUSSION}

\subsection{Metallographic Study}

As seen in Figures 6 and 7, the microstructure images of the UT drill bit have different sizes of white carbide particles in the microstructure. These particles were cryogenic and tempered, and then turned into a fragmented, smaller size and homogeneous structure. In addition, the residue has evolved into austenite, martenzite. The primary cause for developing fine carbide precipitation is supersaturation of martensite with decreasing temperature resulting to lattice distortion and thermodynamically uncertainty of martensite; for this reason, both carbon and alloying elements transmigrate to the nearby defects and set apart there which results in the formation of fine carbides on the after heating up or tempering [19]. The tempering after cryogenic treatment not only remove the thermal stresses of the treatment, but also provides finer carbide precipitation and improves the homogenity of carbide precipitation especially for tempering at $250^{\circ} \mathrm{C}$ (shown with arrows). This resultant microstructure is similar with the microstructures in previous studies [20-22] as the resultant precipitation of fine carbide particles and homogeneous structure of carbides improves mechanical properties such as hardness, toughness, dimensional stability, fatigue resistance, residual stress as well as tribological properties such as coefficient of friction and wear resistance which means tempering after cryogenic treatment is useful.
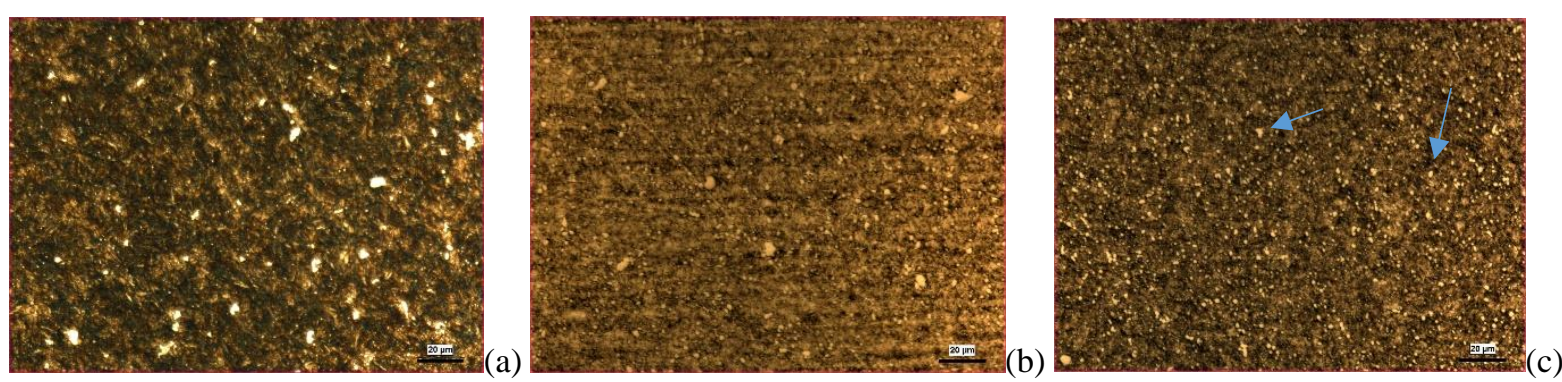

Figure 6. a) UT-500X, b) CTT1-500X, c) CTT2-500X
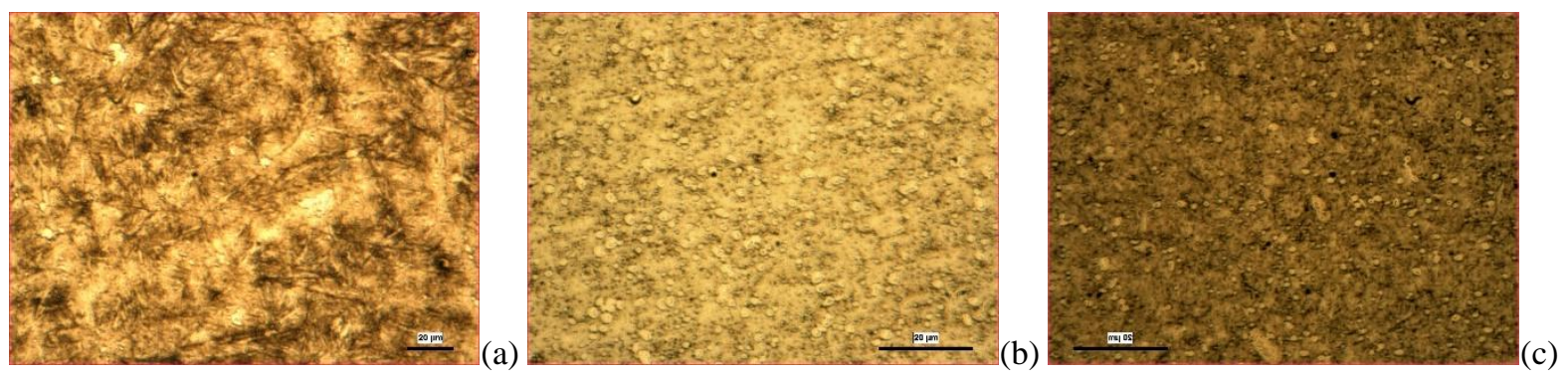

Figure 7. a) UT-1000X, b) CTT1-1000X, c) CTT2-1000X

The SEM images are shown in Figure 8. It was observed that the particles were homogeneously distributed according to SEM images. Also the dimensions of carbide grains have improved in the way of homogenization. It can be understand that the grains have a homogeneous distribution, which affects the hardness and toughness positively. In addition, it is understood from the backscattered electron images that the atomic number of the elements in the light gray and bright regions were found to be higher than the elements in the main phase. Also, it was observed that light regions interacted with carbon and formed carbides according to elemental quantity. Cicek et al. [21] has claimed that by CTT2 the better wear resistance can be obtained as per most of the researchers there are only two main reason which increase the wear properties and hardness of the material which are the the phase transformation which takes place during cryogenic i.e from austenite to martensite, and the second is the precipitation of carbides in the matrix finer the carbide particles led to less wear of the drill. 

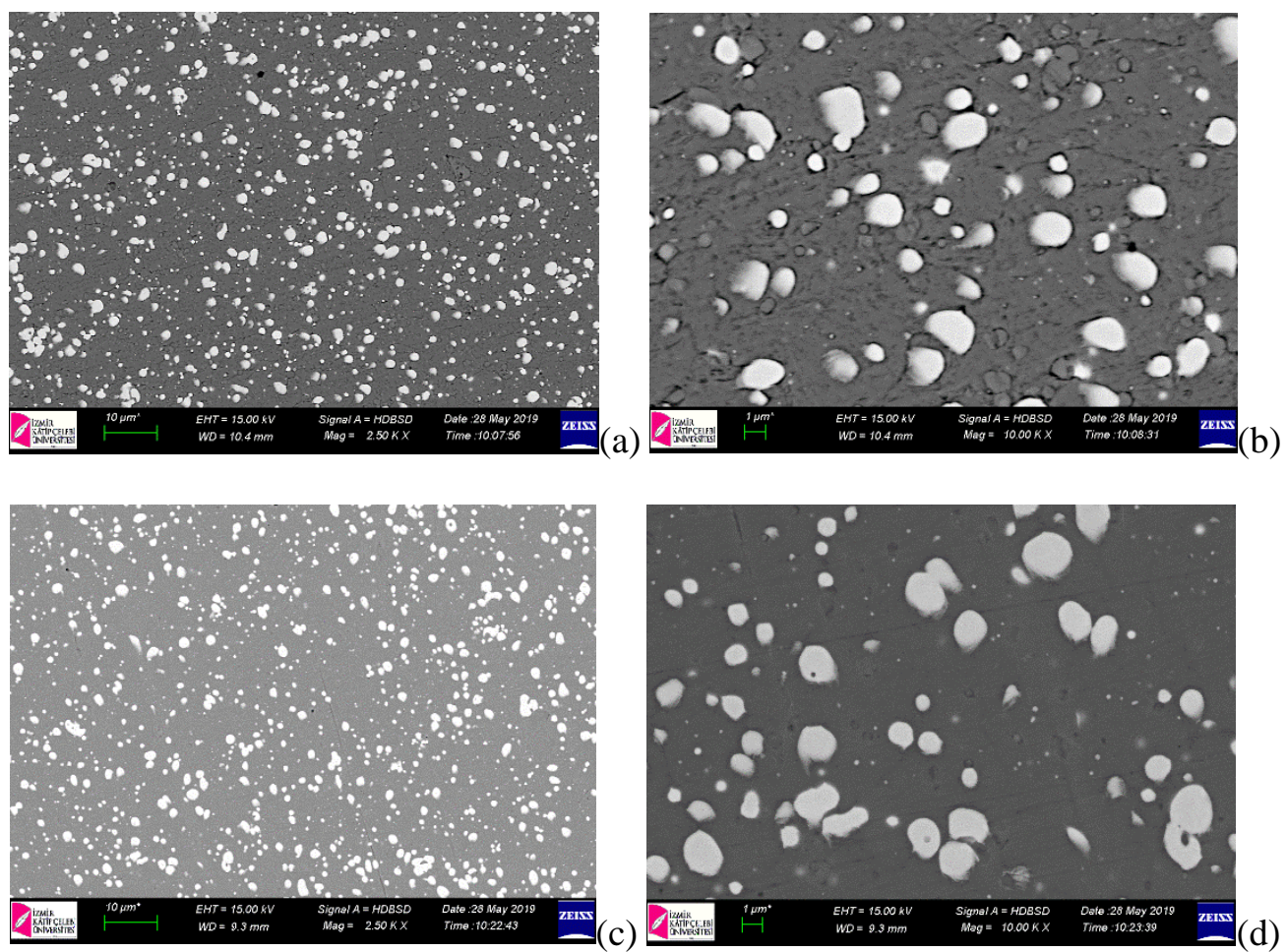

Figure 8. SEM images of (a,b) CTT1, (c,d) CTT2

The analysis zones and EDS spots in SEM-CTT1 are shown in Figure 9 and Tables 3 and 4. For the CTT1 sample, the 1st region (matrix) is rich in terms of iron element and has no oxidized structure. The main region of the 1 st microstructure is acceptable for a HSS steel. The 2 nd region was enriched tungsten (W) element and increased to $3 \%$ to $13 \%$ and molybdenum $\% 2$ to $\% 7.72$ that is because these type carbides would form [17,22] after the cryogenic treatment of HSS steels. Iron (Fe) and manganese (Mn) elements were observed to be decreased compared to the 1st zone. Vanadium (V) and molybdenum $(\mathrm{Mn})$ amounts were also increased. It was observed that there is an increase in the amount of iron $(\mathrm{Fe})$ element in the 3rd region compared to the 1st region. This zone is taken from the interface area where the main phase and the carbide phase formed by the additive material are close. It was observed that the 4 th region is almost the same as the 1 st region.

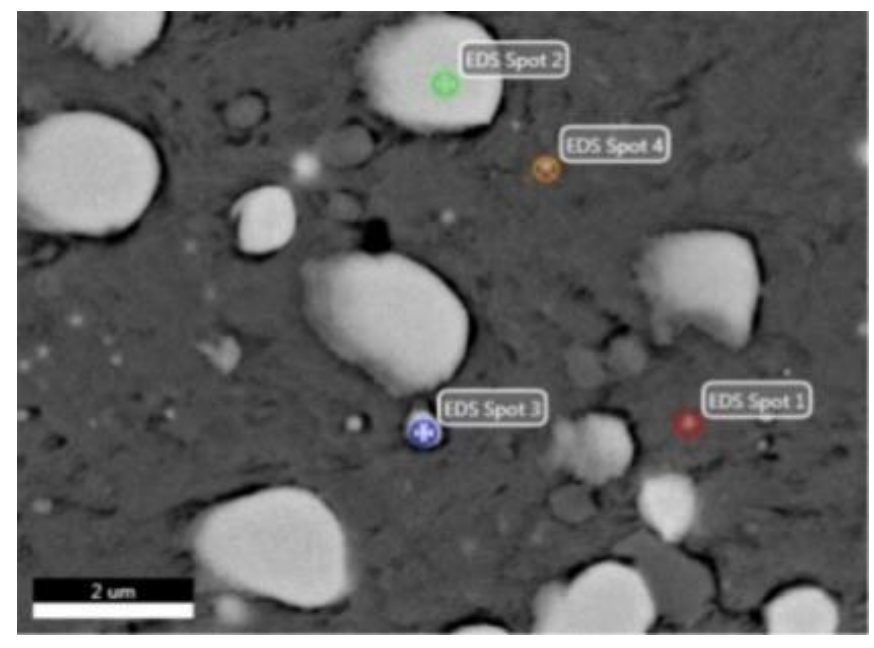

Figure 9. Analysis zones in SEM-CTT1 
Table 3. a) CTT1-SEM EDS Spot 1., b) CTT1-SEM EDS Spot 2.

\begin{tabular}{|c|c|}
\hline Element & Weight, \% \\
\hline $\mathrm{W}$ & 3.04 \\
\hline $\mathrm{Mo}$ & 2.00 \\
\hline $\mathrm{V}$ & 1.47 \\
\hline $\mathrm{Cr}$ & 4.53 \\
\hline $\mathrm{Mn}$ & 0.71 \\
\hline $\mathrm{Fe}$ & 88.25 \\
\hline
\end{tabular}

(a)

\begin{tabular}{|c|c|}
\hline Element & Weight, \% \\
\hline $\mathrm{W}$ & 13.54 \\
\hline $\mathrm{Mo}$ & 7.72 \\
\hline $\mathrm{V}$ & 2.51 \\
\hline $\mathrm{Cr}$ & 5.00 \\
\hline $\mathrm{Mn}$ & 0.48 \\
\hline $\mathrm{Fe}$ & 70.75 \\
\hline
\end{tabular}

(b)

Table 4. a) CTT1-SEM EDS Spot 3., b) CTT1-SEM EDS Spot 4.

\begin{tabular}{|c|c|}
\hline Element & Weight, \% \\
\hline $\mathrm{W}$ & 3.52 \\
\hline $\mathrm{Mo}$ & 2.35 \\
\hline $\mathrm{V}$ & 1.54 \\
\hline $\mathrm{Cr}$ & 4.52 \\
\hline $\mathrm{Mn}$ & 0.67 \\
\hline $\mathrm{Fe}$ & 87.40 \\
\hline
\end{tabular}

(a)

\begin{tabular}{|c|c|}
\hline Element & Weight, \% \\
\hline $\mathrm{W}$ & 2.87 \\
\hline $\mathrm{Mo}$ & 1.87 \\
\hline $\mathrm{V}$ & 1.38 \\
\hline $\mathrm{Cr}$ & 4.48 \\
\hline $\mathrm{Fe}$ & 89.39 \\
\hline
\end{tabular}

(b)

The analysis zones and eds spots for CTT2 sample are shown in Figure 10 and Table 5. The matrix contains the common elements of HSS steels including smaller C content $(0.25 \%)$ which means that some amount of $\mathrm{C}$ is spent for carbide formation. This analysis is parallel with many studies issued cryogenic treatment of HSS steels $[3,6,17]$. The decrease in the amount of iron element in the 2nd region and an increase in the amount of formed secondary phases were observed. The reason for the decrease in the amount of carbon in the 1st region may be due to the tendency of carbide forming with the carbon element of the alloying elements as parallely found in other studies $[3,17,18]$.

It is known that the cutting tool performance depends on the carbide properties in the microstructure of HSS steels. With cryogenic treatment and tempering, the carbide particles would be decreased in size and would exhibit much better distribution. It is possible to see a decrease in the size of the particles and a more uniform distribution of these particles due to the dissolution of the precipitates and the fracture of large particles. With the decrease in the size of the carbide particles and their uniform distribution, the interior stresses in the martensite structure are relieved and the micro-cracking sensitivity is minimized, thus providing a significant improvement in the hardness and wear resistance. The precipitation of fine carbides as a result of cryogenic treatment is responsible for the improvement in the wear resistance $[3,17,22]$. 


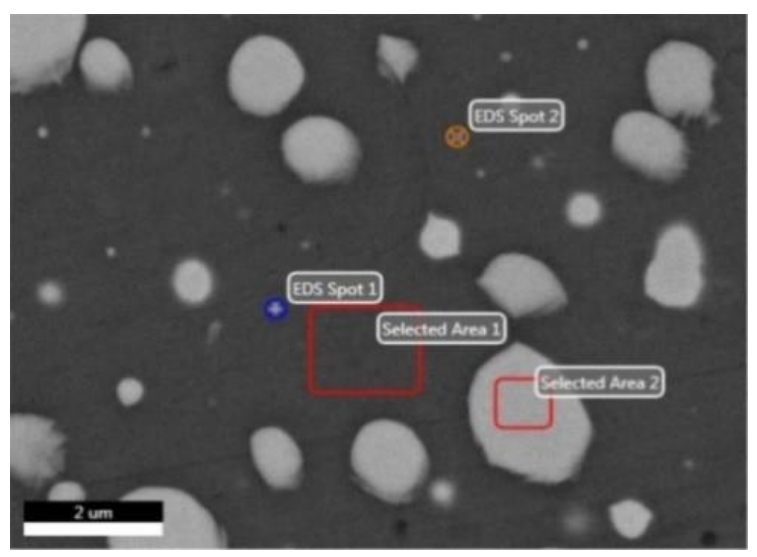

Figure 10. Analysis zones in SEM-CTT2.

Table 5. a) CTT2-SEM Selected Area 1., b) CTT2-SEM Selected Area 2.

\begin{tabular}{|c|c|}
\hline Element & Weight, \% \\
\hline $\mathrm{C}$ & 0.25 \\
\hline $\mathrm{W}$ & 2.36 \\
\hline $\mathrm{Mo}$ & 1.85 \\
\hline $\mathrm{V}$ & 1.45 \\
\hline $\mathrm{Cr}$ & 4.18 \\
\hline $\mathrm{Mn}$ & 0.67 \\
\hline $\mathrm{Fe}$ & 89.24 \\
\hline
\end{tabular}

(a)

\begin{tabular}{|c|c|}
\hline Element & Weight, \% \\
\hline $\mathrm{C}$ & 0.99 \\
\hline $\mathrm{W}$ & 18.58 \\
\hline $\mathrm{Mo}$ & 10.81 \\
\hline $\mathrm{V}$ & 2.84 \\
\hline $\mathrm{Cr}$ & 4.73 \\
\hline $\mathrm{Mn}$ & 0.59 \\
\hline $\mathrm{Fe}$ & 61.66 \\
\hline
\end{tabular}

(b)

\subsection{Drilling Test Results}

\subsubsection{Tool wear test results}

In this study, the CTT drills showed better performance than the UT drill. The performance mostly depends on the formation and homogeneous distribution of carbides after cryogenic processing and also on their hardness. As a result of 30 drilling experiments, the UT drill bit has the highest wear rate on all three workpieces. The minimum wear rate for 3 drill groups was seen in the sphero workpiece, which is considered to be softer than the other two workpieces. The reduction in the diameter of drills is shown in Figure 11. 


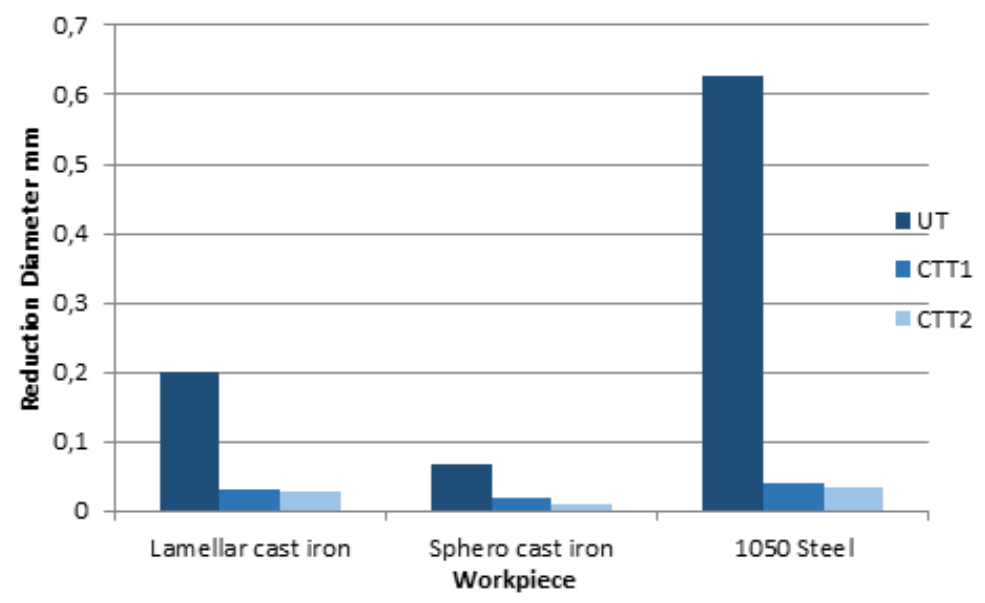

Figure 11. Reduction in the diameter of drills.

In Figures 12-14, it is clear that the untreated drill bit has a more abrasive surface than the cryogenic treated drill bits. The cryogenically treated drill bits with different tempering temperatures were found to have improved wear resistance at $250^{\circ} \mathrm{C}$. The cryogenic process affected positively the wear of M2 tool steel. The most effective wear on the tool life of M2 material in drilling operations is the flank and crater wear. When the types of wear seen in the cutting tools are examined, it is observed that even though the same amount of hole drilling is performed in the conventional heat treatment team, there is much more wear on the outer corner. Because of the wear resistance, toughness and hardness of the cryogenic treated tools, they can perform the drilling process with longer and less wear amount.
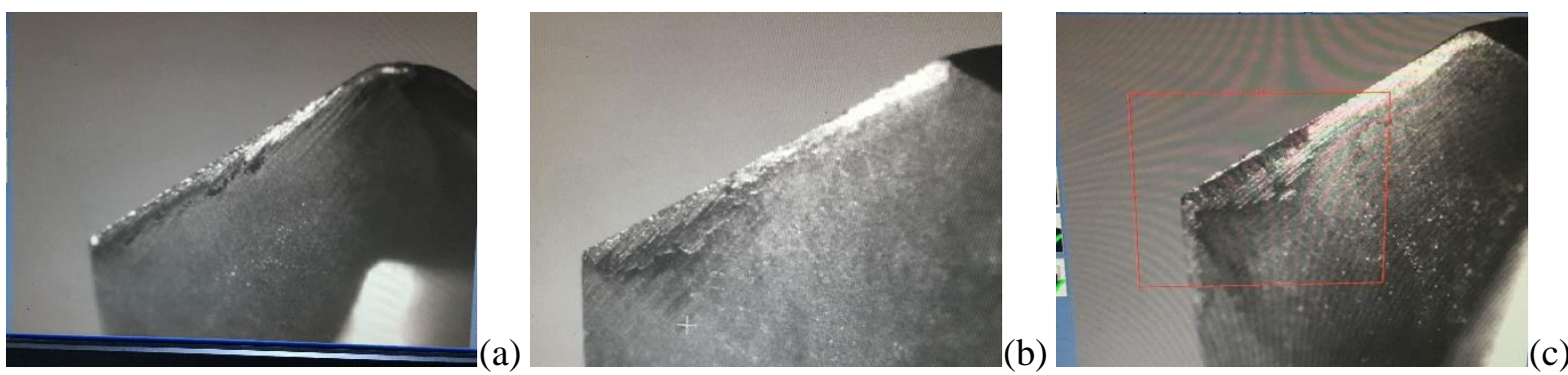

Figure 12. a) UT-Lamellar after 30 holes, b) UT-Sphero after 30 holes, c) UT-Steel after 30 holes.
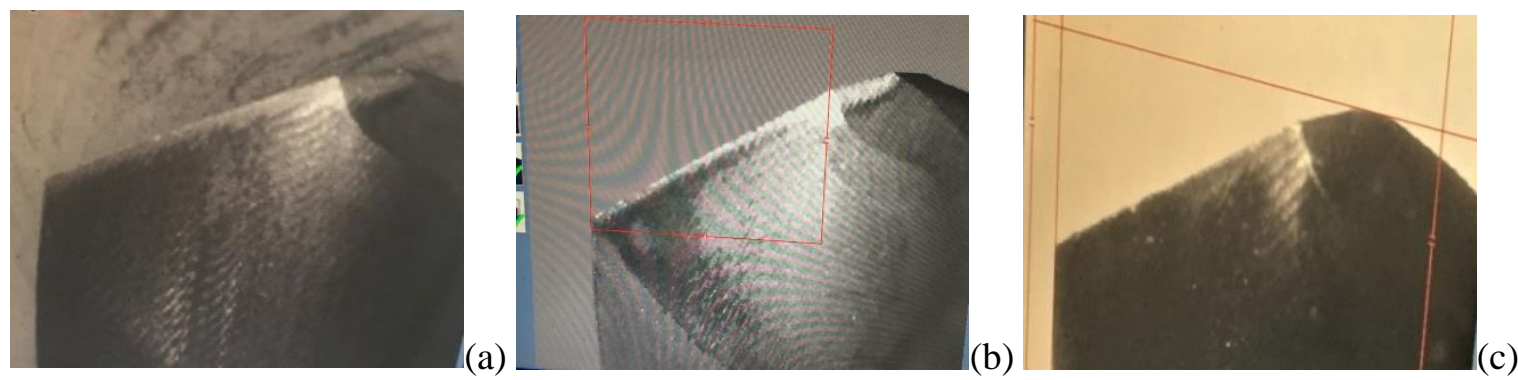

Figure 13. a) CTT1-Lamellar after 30 holes, b) CTT1-Sphero after 30 holes, c) CTT1-Steel after 30 holes. 
Avcı et al. / Eskişehir Technical Univ. J. of Sci. and Tech. A-Appl. Sci. and Eng. 21 (1)-2020
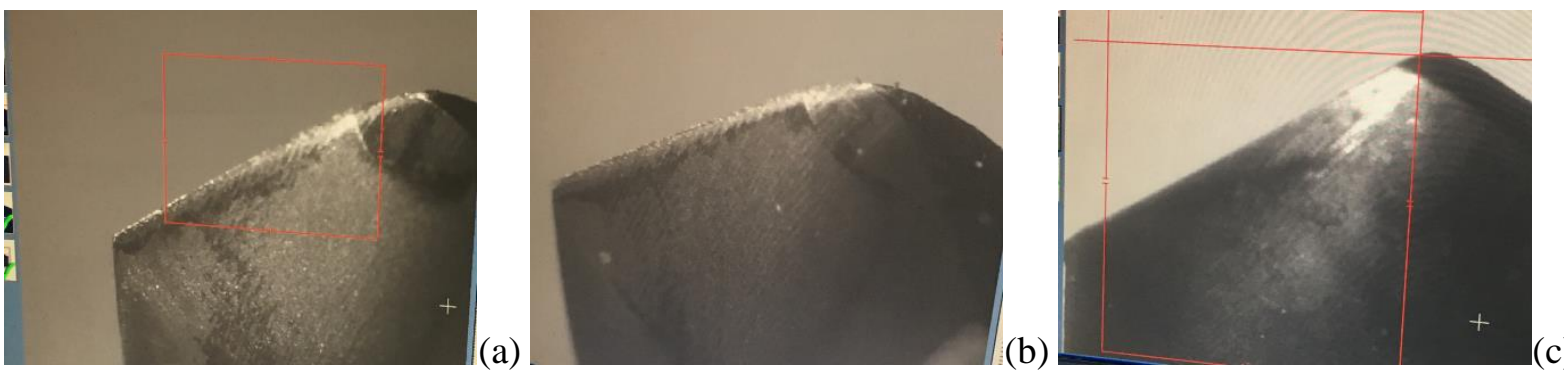

Figure 14. a) CTT2-Lamellar after 30 holes, b) CTT2-Sphero after 30 holes, c) CTT2-Steel after 30 holes.

\subsubsection{Hardness test results}

The microhardness measurements for both the untreated and the treated specimens are shown in Figure 15.

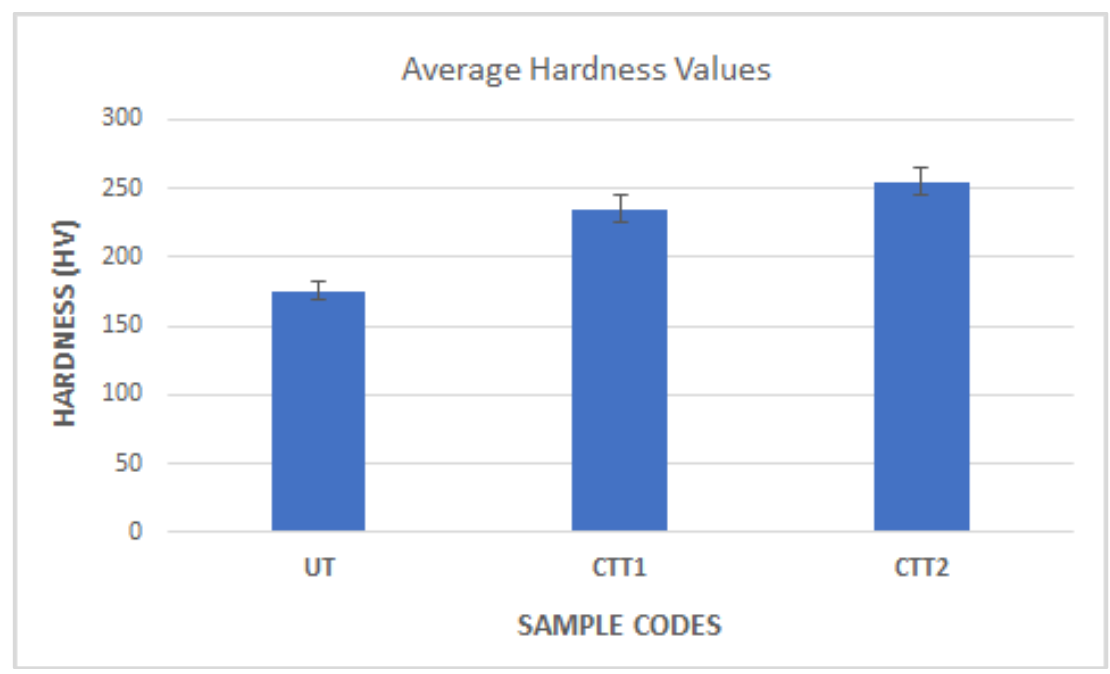

Figure 15: Average hardness values of the samples with standart deviations.

The hardness values of all treated specimens were advanced than that of the untreated specimen. This status was because cryogenic treatment formed new eta carbide particles in the microstructure of the turning adds and monotonous and homogeneously distribution of small-sized carbide particles [23]. The fine $\eta$ carbides present in the inserts obtained using cryogenic treatment develops the hardness and wear resistance without significantly influencing the toughness. Another consequence of this study is that the cryogenic process transformed more residual austenite martensite to a higher volume and hence increased hardness paralel to the previous studies [22, 24]. This improved hardness would also improve the wear resistance and the tool life as also Kivak et al. [22] showed that there was a strong relationship between the microstructure hardness and the wear properties of steel.

\subsubsection{Tool Life (Fracture Test) Results}

The compare the drill life of three drill groups is shown in Figure 16. The UT drill has completed the tool life after 3 holes, the CTT1 19 holes and the CTT2 23 holes. CTT drills have a longer tool life compared to UT because the austenite martensite conversion in the tool steel after cryogenic processing increases the hardness of the tool steels due to the second carbide precipitation and the homogeneous carbide distribution in the microstructure. It is noteworthy that the drill life is approximately around 600\% increase in the CTT1 drill and approximately around \%800 increase in the CTT2 drills. A maximum increase in tool life can be 
seen by achieving a maximum hardness value and a minimum wear rate at a temperature of $250{ }^{\circ} \mathrm{C}$. It is well-known that cryogenic treatment (including tempering) of HSS steels not only improves mechanical properties such as hardness (by the formation of fine carbide precipitates) $[14,21]$ and toughness (by reducing the alloy content of the Fe based matrix) [17] but also remove thermal stresses [20] of the material. In our case, the precipitates of CTT2 sample contain more W and Mo elements which means that there is more $\mathrm{W}$ and Mo depletion from the matrix. Therefore, we suggest that the higher tool life of CTT2 material could be not only due to its higher hardness but also its higher toughness since the matrix of CTT2 has less W and Mo content (2.3 and 1.8\%) compared to CTT1 (3 and 2\%) as seen from Tables 3 and 5. Another reason of better tool life might be because the higher tempering temperature could result in better stress-relief as parallel with other studies [20, 21].

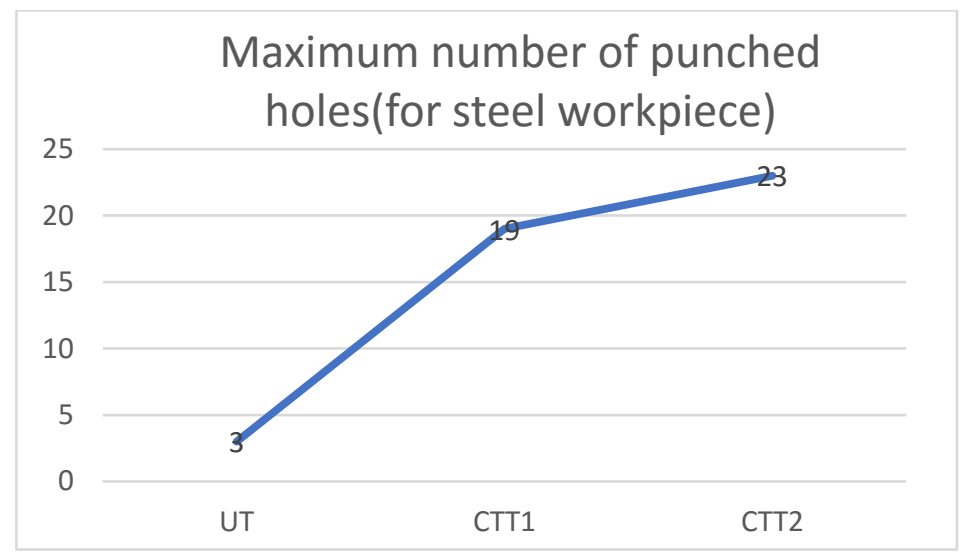

Figure 16. Maximum number of holes for drills during fracture testing.

Images of the chips formed after tests are shown in Figures 17-19. In the three material groups, it was observed that the drill bit, which had been tempered at $250{ }^{\circ} \mathrm{C}$ when compared in three workpieces which had been punched, had a discontinuous chip form due to the harder structure. This situation is supported by hardness test values. Continuous chip formation was observed in the drilling operations on the steel workpiece, which is the most ductile material among the workpieces.
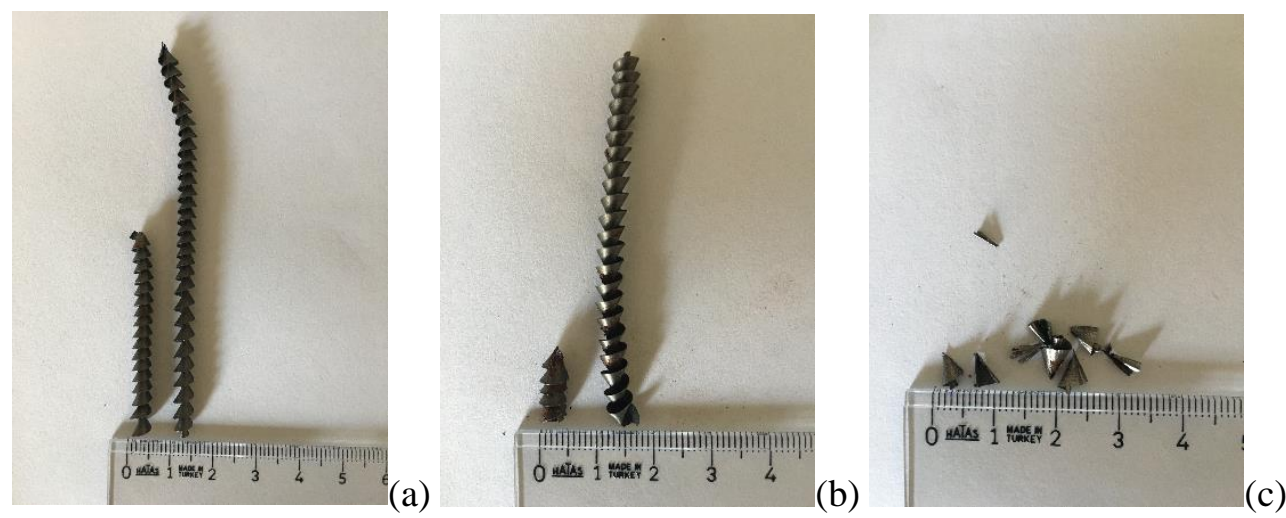

Figure 17. Chips of a) UT, b) CTT1, c) CTT2 samples drilled lamellar cast iron. 

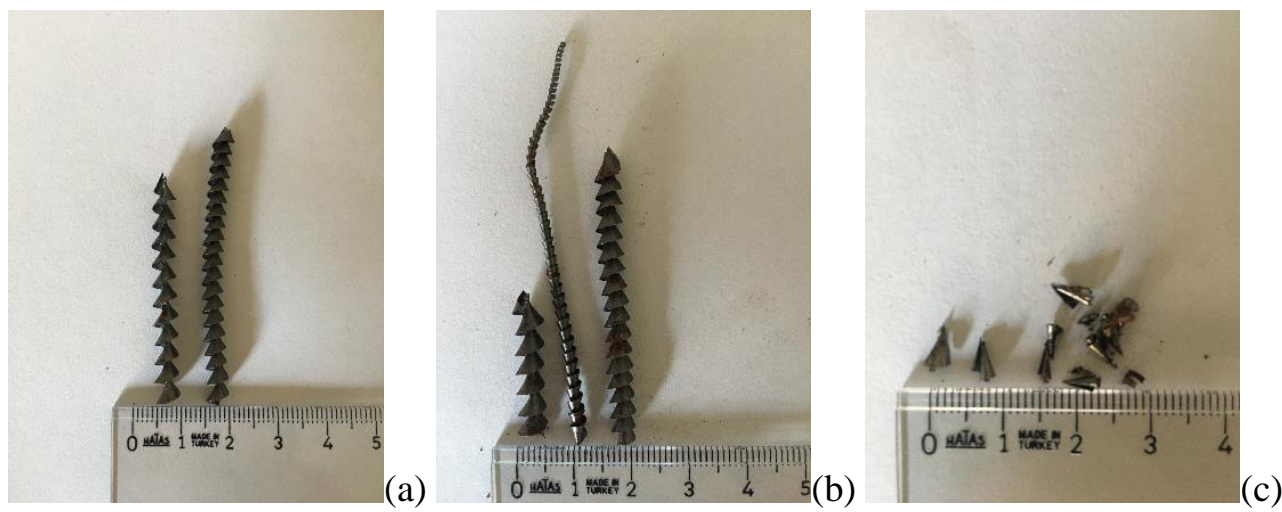

Figure 18. Chips of a) UT, b) CTT1, c) CTT2 samples drilled on spheroidical cast iron.
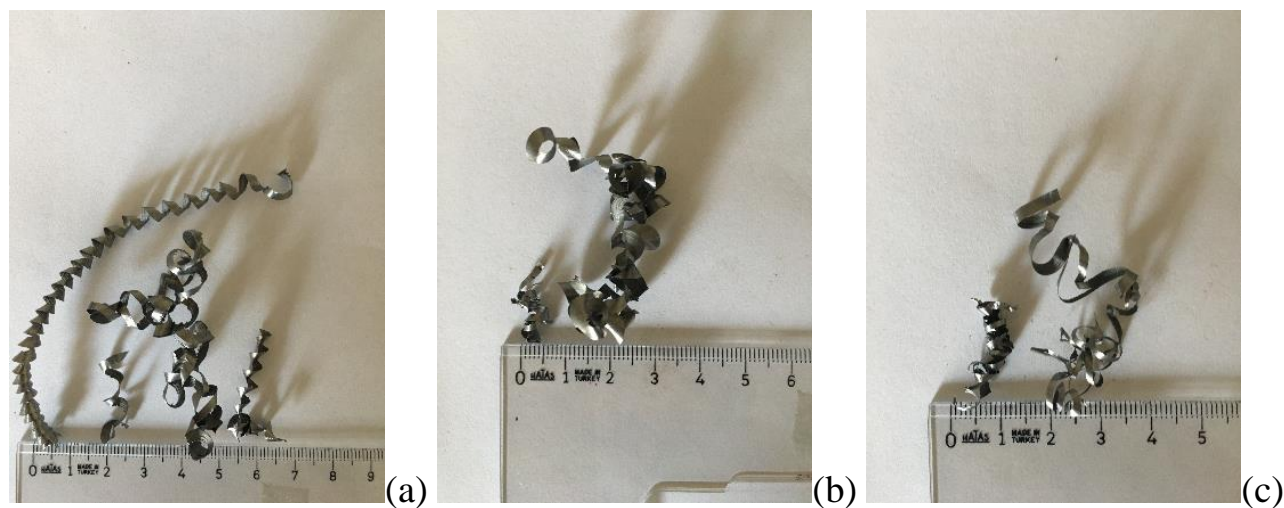

Figure 19. Chips of a) UT, b) CTT1, c) CTT2 samples drilled on steel.

\section{CONCLUSION}

Unlike traditional heat treatment, cryogenic process is not a superficial method; affects all material. By homogenizing the carbide distribution with them, it increases the toughness and hardness values of the cutting tools. The cryogenic process applied to the cutting tools increases tool wear resistance and tool life-time because of enhancements in mechanical properties. The ideal tempering temperature maintaining optimal of the cryogenic process is $250{ }^{\circ} \mathrm{C}$. The cryogenic process drill bit at this temperature has the best performance in mechanical tests. It has been observed that the tempered drill bit at $250{ }^{\circ} \mathrm{C}$ with cryogenic treatment has the most ideal form in terms of hole surface quality and drill wear together with the chip form it creates during drilling operations. The development of abrasion resistance is mainly due to the conversion of the residual austenite to martensite and the formation of fine, homogeneous carbide particles during cryogenic treatment. This is supported with images taken from the optical microscope and according to SEM images, there are iron elements in the matrix region. The additive elements formed the carbides by interacting with the carbon and these carbide regions were seen as light gray areas in the images taken. In addition, it was observed that the carbides formed had similar dimensions with more uniform distribution and particle size by cryogenic process and after tempering process. It can be said that it additional cryogenic treatment contributes to diffusion wear resistance, hardness and tool life by decreasing carbon ratio due to homogeneous distribution of carbides. In addition, the conversion of retained austenite to martensite plays an effective role in improving hardness values. In fracture tests, up to $800 \%$ of tool life observed in cryogenic process drills compared to conventional drill bits supports the cryogenic process to improve the mechanical properties of the material. 
Avcı et al. / Eskişehir Technical Univ. J. of Sci. and Tech. A-Appl. Sci. and Eng. 21 (1)-2020

\section{ACKNOWLEDGEMENT}

The authors would like to acknowledge Oğuzcan Güzelipek and Anil Kaplan for their assistance to organize the drilling tests.

\section{REFERENCES}

[1] Chattopadhyay AB. Machining and Machine Tools. 1st ed. Delhi, INDIA: Wiley, 2011.

[2] Bayer AM, Becherer BA, Vasco T. High Speed Tool Steels. ASM Handbook, Volume 16: Machining ASM Handbook Committee, p 51-59.

[3] Akincioglu S, Gokkaya H, Uygur I. A review of cryogenic treatment on cutting tools. Int J Adv Man Tech 2015; 78: 1609-1627.

[4] Nasir I, The effect of heat treatment on the mechanical properties of stainless steel type 304. Int J Sci Eng and Res (IJSER) 2014; 3: 87-93.

[5] Singh R, Heat Treatment of Steels. Applied Welding Engineering 2016: Elsevier Science.

[6] Shaojun S, Xianping Z, Chengtong S. Heat-treatment and properties of high-speed steel cutting tools. IOP Conference Series Materials Science and Engineering 2018; 423: 1-6.

[7] Bepari MMA, Surface and Heat Treatment Processes, in Comprehensive Materials Finishing, 2017.

[8] Geller YA, Artyukhov VF. Effect of annealing on the properties of high-speed steels. Metal Sci Heat Treatment 1976; 18: 940-963.

[9] Stoicanescu M, Ene E, Zara A, Giacomelli I, Crisan A. The heat treatment influence of 1.3343 high speed steel on content of residual austenite. Proc Tech 2016; 22: 161-166.

[10] Kadirgama K, Noor MM, Sharma KV. Tool life and wear mechanism when machining hastelloy C-22HS. Wear 2011; 270: 258-268.

[11] Grzesik W. Advanced Machining Processes of Metallic Materials. 2nd Edition; Elsevier, 2008.

[12] Özbek NA, Çiçek A, Gülesin M, Özbek O. Effect of cutting conditions on wear performance of cryogenically treated tungsten carbide inserts in dry turning of stainless steel. Trib Int 2016; 94: 223-233.

[13] Deshpande RG, Venugopal KA. Machining With Cryogenically Treated Carbide Cutting Tool Inserts. Mater Today: Proc 2018; 5: 1872-1878.

[14] Dhande ST, Kane VA, Dhobe MM, Gogte CL, Influence of soaking periods in cryogenic treatment of tungsten carbide. Proc Manuf 2018; 20: 318-328.

[15] Giusti F, Santochi M, TANTUSSI, G. On-line sensing of flank and crater wear of cutting tools, CIRP, 1987; 1: 41-44.

[16] Narasimha M, Sridhar K, Kumar RR, Kassie AA. Improving Cutting Tool Life a Review, Int J Eng Res Dev 2013; 7: 67-75. 
[17] Firouzdor V, Nejati E, Khomamizadeh F. Effect of deep cryogenic treatment on wear resistance and tool life of M2 HSS drill. J Mat Proc Tech 2008; 206: 467-472.

[18] Cicek A, Kivak T, Uygur I, Ekici E, Turgut Y. Performance of cryogenically treated M35 HSS drills in drilling of austenitic stainless steel. Int J Adv Manuf Tech 2012; 60: 65-73.

[19] Krauss G, Tempering of martensite in carbon steels. In: Phase Transformations in Steels: Diffusionless Transformations High Strength Steels Modelling and Advanced Analytical Techniques, 2012.

[20] Kumar S, Khedkar NK, Jagtap B, Singh TP. The Effects of Cryogenic Treatment on Cutting Tools. IOP Conf Ser Mater Sci Eng 2017; 225: 012104.

[21] Cicek A, Kara F, Kıvak T, Ekici E, Uygur I. Effects of deep cryogenic treatment on the wear resistance and mechanical properties of AISI H13 hot-work tool steel. J Mater Eng Perfor 2015; 24:4431-4439.

[22] Kıvak T, Şeker U. Effect of cryogenıc treatment applied to M42 HSS drills on the machinability of Ti-6Al-4V alloy. Mater Tech 2015; 49(6): 949-956.

[23] Padmakumar M, Dinakaran D, Guruprashat J. Characterization of cryogenically treated cemented carbide. Integrated Ferroelectrics 2017; 185: 65-72.

[24] Priyadarshini A. A Study Of The Effect Of Cryogenic Treatment On The Performance Of High Speed Steel Tools And Carbide Inserts. MSc, National Institute of Technology Mechanical Engineering, Rourkela, Indie, 2007. 